\title{
Study of tributary inflows in Lake Iseo with a rotating physical model
}

\author{
Marco PILOTTI, ${ }^{1 *}$ Giulia VALERIO, ${ }^{1}$ Luca GREGORINI, ${ }^{1}$ Luca MILANESI, ${ }^{1}$ Charlie A.R. HOGG $^{2}$ \\ ${ }^{1}$ Department of Civil Engineering, Architecture, Land, Environment and Mathematics (DICATAM), University of Brescia, Via Branze 43, \\ Brescia, Italy; ${ }^{2}$ Institute of Theoretical Geophysics, Department of Applied Mathematics and Theoretical Physics, University of \\ Cambridge, UK \\ * Corresponding author: marco.pilotti@ing.unibs.it
}

\begin{abstract}
The influence of Coriolis force on the currents of large lakes is well acknowledged; very few contributions, however, investigate this aspect in medium-size lakes where its relevance could be questionable. In order to study the area of influence of the two major tributary rivers in Lake Iseo, a rotating vertically distorted physical model of the northern part of this lake was prepared and used, respecting both Froude and Rossby similarity. The model has a horizontal length scale factor of 8000 and a vertical scale factor of 500 and was used both in homogeneous and in thermally stratified conditions. We explored the pattern of water circulation in front of the entrance mouth for different hydrologic scenarios at the beginning of spring and in summer. We neglected the influence of winds. The primary purposes of the model were twofold: i) to increase our level of knowledge of the hydrodynamics of Lake Iseo by verifying the occurrence of dynamical effects related to the Earth's rotation on the plume of the two tributaries that enter the northern part of the lake and ii) to identify the areas of the lake that can be directly influenced by the tributaries' waters, in order to provide guidance on water quality monitoring in zones of relevant environmental and touristic value. The results of the physical model confirm the relevant role played by the Coriolis force in the northern part of the lake. Under ordinary flow conditions, the model shows a systematic deflection of the inflowing waters towards the western shore of the lake. The inflow triggers a clockwise gyre within the Lovere bay, to the West of the inflow, and a slow counter-clockwise gyre, to the East of the inflow, that returns water towards the river mouth along the eastern shore. For discharges with higher return period, when only the contribution by Oglio River is relevant, the effect of the Earth's rotation weakens in the entrance zone and the plume has a more rectilinear pattern, whilst in the far field the current driven by the inflows keeps moving along the western shore. On the basis of these results one could expect that the north-western part of the lake between Castro and Lovere, although not aligned with the tributaries' axes, is more sensitive to accumulation effects related to river-borne pollution. The results obtained with the physical model are critically compared with data obtained from different sources: the trajectory of a lagrangian drogue; a map of reflectivity data from the lake floor; a map of water turbidity at the intrusion depth. The findings are also confirmed by the results of a 3D numerical model of the lake.
\end{abstract}

Key words: Coriolis force, physical model, lake currents, Lake Iseo.

Received: April 2013. Accepted: September 2013.

\section{INTRODUCTION}

Lake Iseo is a deep Italian lake (maximum depth of about $256 \mathrm{~m}$ ) located in the subalpine area of central-eastern Lombardy, characterized by a water surface area $\left(\mathrm{a}=60.88 \mathrm{~km}^{2}\right)$ and a volume $\left(\mathrm{V}=7.9 \times 10^{9} \mathrm{~m}^{3}\right)$ that makes it the fifth largest Italian lake. Since the seventies Lake Iseo has undergone a progressive deterioration of water quality, with a transition from oligotropy to eutrophy. The transition has been caused by the high nutrient load from the drained watershed and to the oligomictic behaviour observed during the last decades, possibly amplified by the increase in deep water salinity (Brizzio et al., 2001) and by climatic fluctuations. As a matter of fact, after the complete mixing in 1981, a full circulation occurred only twice, in 2005 and 2006. Accordingly, a marked decrease of hypolimnetic oxygen concentration has been observed and anoxia has been established below $200 \mathrm{~m}$ since 1994, with short interruptions after the above-mentioned circulation events. The dramatic decrease of the oxygen con- tent of the deeper part of the lake (Garibaldi et al., 1999; Ambrosetti and Barbanti, 2005) has been recently confirmed by an extensive campaign conducted by Pilotti and Valerio in 2012 (unpublished data) that showed that 29\% of the lake volume has an oxygen concentration below the $2 \mathrm{mg} / \mathrm{L}$ threshold during summer, and $39 \%$ of the volume below a $4 \mathrm{mg} / \mathrm{l}$ threshold. Accordingly, there is an urgent need of deepening our level of understanding of the overall dynamics of this lake in order to calibrate further nutrient load reductions and to tune specific recovery actions that may influence its chemistry and ecology. This is also required by the European Water Framework Directive that dictates that all member countries must restore good ecological quality in natural lakes by 2015 , where the term good ecological quality means the oligotrophic reference state (Bonomi and Gerletti, 1967) from which the future ecological condition of the lake will be allowed to deviate only slightly. This target seems an ambitious task in a strongly urbanized watershed like that of Lake Iseo. 
Although already suggested by Bonomi and Gerletti (1967), who underlined the study of the circulation mechanics of this lake as a priority, only recently a set of experimental and modelling activities have been accomplished to specifically investigate its internal hydrodynamics (Pilotti et al., 2013), with a focus on the internal wave structure (Valerio et al., 2012; Vilhena et al., 2013) and on plunging at the entrance of the Oglio River (Hogg et al., 2013). Beside the internal movements triggered by the wind, inflows-induced currents are also central to the understanding of oxygenation, deep-water renewal and nutrient transport in deep lakes. Typically, most of the nutrient and bacterial loading to a lake comes from its tributaries. Accordingly, the dilution, the intrusion depths, and the horizontal extent and path of the inflows strongly condition both the primary production in the surface layer and the public health risk posed by pathogens.

In the northern part of Lake Iseo two main tributaries are present: Oglio River (T1 in Fig. 1) and Industrial canal (T2 in Fig. 1). They drain Vallecamonica, a valley that contributes to approximately $82 \%$ of the total inflow to Lake Iseo and where about $40 \%$ of sewage waters are still untreated. As a collecting sewer system has been completed around the lake, the most significant source of pol-
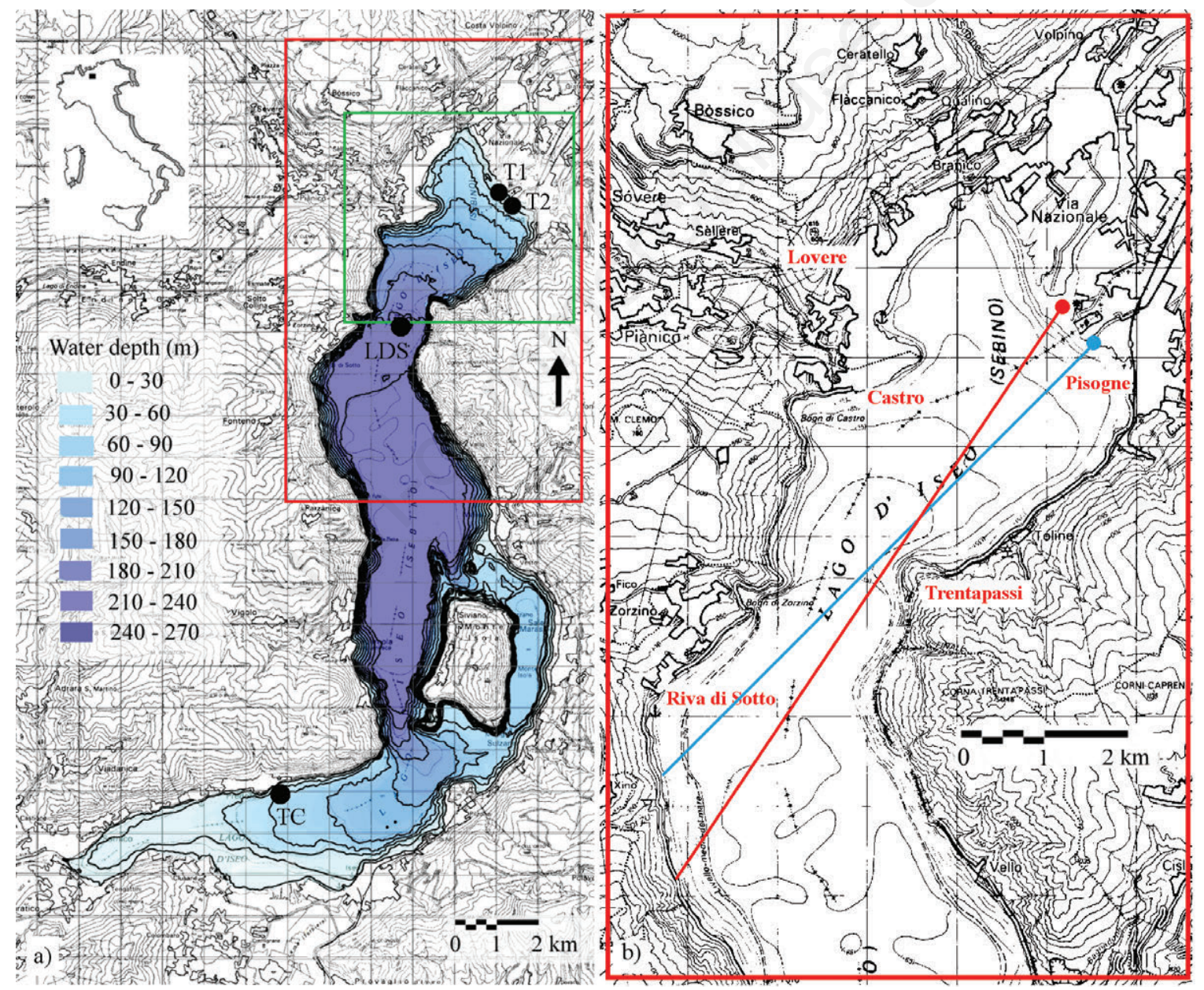

Fig. 1. Geographical setting of Lake Iseo, along with its bathymetry, represented with isodepth lines at $30 \mathrm{~m}$ spacing (a). The location of the two main tributaries is shown as T1 (Oglio River) and T2 (Industrial canal). LDS and TC mark the position of the floating stations where the temperature profiles are monitored. The physical model encompasses the area enclosed within the outer rectangle, whilst the investigated area is enclosed within the inner rectangle. The area is enlarged on the right (b) where the straight lines show the directions of the tributaries axis at their entrance in the lake. 
lution is now the internal load coming from the bottom sediments and by the two tributaries. On the other hand, some of the most important touristic resorts of the lake, such as the villages of Lovere, Pisogne Castro and of Riva di Solto, are located around the northern part of the lake. Accordingly, the quality of surface waters may be of direct concern for the local economy. Recent surveys of the Azienda Sanitaria Locale (Local Health Authority) of the Province of Bergamo have shown that in some locations along the western shoreline coliform and bacterial pollution is still present. These pollution events occur at times that are not easily explained by the overflows from the existing sewer system. A possible explanation to these observations could be provided by the direct influence of the wastewaters from Vallecamonica, but a more definite answer to this question requires a better knowledge of the influence areas of the tributaries. This would also be important for mapping the areas of deposition of the transported fine sediments, that potentially can contribute to the lake internal nutrients load.

The first observations on the path followed by the waters of the Oglio River in the lake were provided by Salmoiraghi (1898), who in the first study on the limnology of Lake Iseo observed that during the floods of the Oglio River, the lake waters remain clear or become opal in front of the village of Castro, but it muddies in front of the town of Riva, where the shore is rocky and has no tributaries. It seems that the murky waters of the Oglio River sink at the mouth and rise again to the surface somewhere. This fact, which I have not yet studied, seems independent from the winds... Although the Oglio mouth has slightly rotated its alignment in an eastward direction during the last century, the original Salmoiraghi's hypothesis on the possible occurrence of interflow in Lake Iseo is now supported by our experimental activities that, through a regular monitoring of the tributary's temperature, has shown that interflow happens regularly in this lake. It is interesting to note that the observation by Salmoiraghi evidences a reemergence of the plume, that is not related to bathymetric effects. This is possible under the action of internal waves, that may distort the submerged cloud and play a strong role in the transport of the interflow to the surface, as clearly shown, e.g., by Fischer and Smith (1983). Other interesting observations come from a recent bathymetric survey of the lake that showed the presence of channels on the alluvial delta in the northern part of the lake, down to the depth of $150 \mathrm{~m}$ (Bini et al., 2007). These channels clearly show that occasionally plunging flow characterizes the tributary water. Although a recent study (Hogg et al., 2013) theoretically investigated this mechanism of plunging, to the knowledge of the authors, no previous study has ever investigated the horizontal path of the inflow intrusion.

Finally, an experiment accomplished with a drogue deployed in front of T2 and detailed in the following, showed that typical velocities $v$ of the interflow in correspondence of ordinary discharges decrease from 0.06 to $0.02 \mathrm{~m} / \mathrm{s}$ over a distance $\mathrm{L}=3000 \mathrm{~m}$. A measure of the significance of rotation is provided by the Rossby number, which can be regarded as the ratio between the convective acceleration and the local Coriolis acceleration. Accordingly, if $\omega_{P}$ is the angular velocity of the Earth and $\varphi$ the latitude, $R o=v / 2 \omega_{P} \sin (\varphi) L \approx 0.13$, so that one can expect rotation to be important in such conditions. Given the low value of the Rossby number, it is reasonable to expect that Earth's rotation also remains significant for considerably higher discharges.

Here we report the results obtained with the construction of a physical model to explore the interplay between the discharge of the tributaries and the Earth's rotation. To this purpose, the model was mounted on a rotating table. The model also takes into account the effects of density stratification, considering both winter and summer conditions. Since the primary purpose is that of studying individually the tributary plume dispersion in a limited portion of the lake, here the role of wind stress is neglected, as done in other physical models (Wright and Nydegger, 1980; Rumer and Robson, 1968). Accordingly, our study cannot provide direct indication on the overall current flow field which is present in the northern part of Lake Iseo and should not be regarded as a comprehensive lake management tool. However, we believe it is important to analyse singularly the different physical processes acting on the lake. If one considers that Coriolis force acts continuously on the lake waters, independently from the wind field that has a marked time variability, one may expect that the analysis of this single dynamic effect can provide insights on medium and long-term observations.

The study of inflows into large lakes using physical models is not new. Previous studies regarded, e.g., Lake Erie (Rumer and Robson, 1968), Lake Ontario (Li et al., 1975) and Lake Constance (Stewart, 1988). In all these studies the models were used to explore mouth positions and inflow dispersals under different environmental conditions. More recently, Atkinson et al. (1994) discussed the development of a physical model to study the Niagara river discharge into Lake Ontario, showing clear effects of Earth's rotation on the flow. These studies confirmed the relevance of Coriolis force on lake circulation in the influence areas of the tributaries in the case of large lakes, where the linear scale of the problem is one order of magnitude larger than in Lake Iseo. Given that the effect of Earth's rotation increases in importance with the size of the lake, in medium size lakes it could be counterbalanced and masked by other dynamic effects. Nydegger (1979) briefly argued about the importance of Coriolis force in the deflection of the tributary waters of 3 medium-size Swiss lakes, but he did not provide any quantitative indi- 
cation to assess the validity of the physical model he used. The effects of Coriolis force were also documented by Hamblin and Carmack (1978) in Kamloops Lake, by Morillo et al. (2008) in Coeur d'Alene Lake and mentioned by Laborde et al. (2010) in Lake Como, whose width is comparable to that of Lake Iseo and where the river is deflected towards its right-hand shoreline irrespective of wind conditions.

In recent years this kind of study has been accomplished mostly numerically, since numerical models provide simulations in a cheap, versatile and attractive way. Nevertheless, we believe that a combined methodology of numerical and laboratory analysis gives the opportunity of synergy and mutual validation. On one side, numerical models use simplifying assumptions and use physical values which have large bounds of uncertainty, such as the horizontal and vertical diffusivities. Simulations of large 3D flow fields are often extremely demanding in term of computational resources and stabilising the numerical schemes. On the other side, physical models do not usually account for all the drivers that influence water movements in a lake (e.g., wind distribution, internal waves, Earth's rotation, discharge of the tributaries, lake morphology) and may be affected by the reduced size of the model. A definite advantage of physical models is that of allowing an overall view of the process with visualization capabilities that are unmatched and that can be easily appreciated also by people who may have not a quantitative background, as lake managers or the public. This is particularly important when the economical implications of environmental decisions are huge and must be shared by a wide audience, as in the case involving the lakes of the Italian prealpine areas.

Accordingly, this paper combines experimental and numerical methods to study the impact of Coriolis force on buoyant plumes into a mid-size lake. The results of the physical model clearly show the role played by Coriolis force, that is confirmed also by the comparison with other independent data, such as a map of bottom reflectivity and the results of turbidity measurements accomplished during an extensive campaign in 2012. These results are also supported by the implemented 3D numerical model of the lake which provides a very satisfactory match between the two approaches.

\section{METHODS}

The construction of a physical model relies on similitude criteria derived by the Navier Stokes equations, which govern the flow of Newtonian fluids. These equations can be cast in dimensionless fashion, evidencing the role of two dimensionless numbers: the Reynolds number $(R e)$, whose physical meaning is proportional to the ratio between inertial and viscous forces, and the densimetric Froude $(F r)$ number, that is proportional to the ratio be- tween inertial and gravitational forces. When geostrophic effects are important, also the Rossby number $(R o)$ is present, that represents a ratio between inertial and Coriolis forces. In order to obtain a complete dynamic similitude, these ratios must be the same in the prototype and in the model. However, it can be easily shown that it is not possible to achieve equality of the Reynolds number except by operating with a fluid with a different kinematic viscosity with respect to the prototype, and this procedure is practically inconvenient and often impossible. As discussed in the following, for physical models of large lakes it is widely accepted that Froude number similarity can be sufficient for an accurate reproduction of the process. These similitude criteria imply that $F r_{m}=F r_{p}$, that is

$$
\frac{v_{m}}{\sqrt{\frac{\Delta \rho_{m}}{\rho_{m}} g L_{m}}}=\frac{v_{p}}{\sqrt{\frac{\Delta \rho_{p}}{\rho_{p}} g L_{p}}}
$$

where $m$ and $p$ make reference to the model and to the prototype, respectively, $v$ is the velocity, $\Delta \rho$ is a mass density difference, $g$ is the gravity acceleration and $L$ is a characteristic length. If in the model one maintains the same density ratio present in the prototype, as needed for correct reproduction of stratification effects,

$$
\frac{\Delta \rho_{m}}{\rho_{m}}=\frac{\Delta \rho_{p}}{\rho_{p}}
$$

then (eq. 1) simplifies and can be used as a basis to get the length and time scale of the model. However, it is important here to observe that when the horizontal length scale is much larger than the vertical length scale, the use of the same scale for these two lengths (undistorted model) may prove prohibitive. This is the case for Lake Iseo (and lake modelling in general), where the typical horizontal scale is in the order of $10^{4} \mathrm{~m}$ and the vertical scale is in the order of $10^{2} \mathrm{~m}$. This would lead either to a large model or to a very shallow model, where turbulence is not attained, therefore violating the requirement of independence from $R e$. In such a model, the role of surface tension may be not negligible and it would be impossible to obtain a density stratification or to distinguish stratification effects connected to density differences. Accordingly, it is customary (Harleman et al., 1962; Dortch et al., 1985), to use a distorted scale model, allowing the reproduction of turbulent and stratification effects that are relevant in lake dynamics. In a distorted model two length scale ratios $X_{R}$ and $Y_{R}$ are used, for horizontal and for vertical lengths

$$
X_{R}=\frac{l_{p}}{l_{m}} ; Y_{R}=\frac{h_{p}}{h_{m}}
$$

where $l_{p}, h_{p}$ are the lengths of the prototype in the horizontal and in the vertical direction, respectively, and $l_{m}$, $h_{m}$ are the corresponding lengths in the model. Accordingly, the horizontal area scale ratio is 


$$
A_{X R}=X_{R}^{2}
$$

and the vertical area scale ratio is

$$
A_{Y R}=X_{R} Y_{R} .
$$

It is important to observe that the length that appears in (eq. 1) is in the vertical direction, so that from (eq. 1) one gets the velocity ratio,

$$
V_{R}=\frac{v_{p}}{v_{m}}=\sqrt{\frac{h_{p}}{h_{m}}}=Y_{R}^{1 / 2}
$$

From (eq. 6) it is straightforward to get the time ratio

$$
T_{R}=\frac{t_{p}}{t_{m}}=\frac{X_{R}}{V_{R}}=\frac{X_{R}}{Y_{R}^{1 / 2}}
$$

and eventually, by definition of volumetric discharge $Q=A v$, where $A$ is the cross section area in the vertical direction, as given by the product of a horizontal and of a vertical length, one gets the discharge ratio

$$
Q_{R}=\frac{Q_{p}}{Q_{m}}=X_{R} Y_{R}^{3 / 2}
$$

Finally, if the rotational effects are expected to be important, the ratio of the angular velocities is obtained by imposing the equality of the Rossby number, $R o=v / 2 \omega L$, between prototype and model, $R o_{m}=R o_{p}$, that implies

$$
\omega_{R}=\frac{\omega_{p}}{\omega_{m}}=\frac{Y_{R}^{1 / 2}}{X_{R} \sin \varphi}
$$

where $\omega_{p}$ is the Earth's angular velocity (approximately $\left.7.27 \cdot 10^{-5} \mathrm{rad} / \mathrm{s}\right), \omega_{m}$ is the rotation rate for the model, and $\varphi$ the local latitude $\left(45^{\circ} 43^{\prime} 00^{\prime \prime}\right.$ North for Lake Iseo) that accounts for the local rotation rate.

In the following text, our interest will be limited to the study of the inflow in the northern part of Lake Iseo. In order to minimize the $X_{R}$ ratio, we decided to reproduce only one half of the lake, after having verified, by using a 3D numerical model presented in the following, that the cut-off of the southern basin did not modify the flow field caused by the tributaries in the northern part of the lake. Accordingly, the model cannot be used to study seiches or internal waves, whose period would require the whole lake extension. Internal waves have already been investigated in the field and numerically (Valerio et al., 2012), and surface seiches have already been studied (Peronaci, 1949a, 1949b). However, the experimental assessment requires knowledge of water level elevations at specific points in the lake in response to known wind forcing in order to identify the role of boundary friction ( $\mathrm{Li}$ et al., 1975). These data are not yet available for Lake Iseo. The selected area, shown in Fig. 1, has linear dimensions in the order of $10 \mathrm{~km}$ for the length and $3 \mathrm{~km}$ for the width. On the basis of the rotating table dimension, we selected an $X_{R}$ ratio of 8000 , so that the length of the physical model can be kept below $1.5 \mathrm{~m}$. Typically, the distortion $X_{R} / Y_{R}$ ratio of free surface models varies in the range be- tween 4 and 40, and the ratios reported in the literature for large lakes range in the field $500 \leq Y_{R} \leq 1000$ and 17000 $\leq X_{R} \leq 300000$. In our model we used a $X_{R} / Y_{R}$ ratio of 16 , so that the vertical length ratio (3) is $Y_{R}=500$. Accordingly, the model has a height of $0.52 \mathrm{~m}$, that corresponds to the maximum depth of about $250 \mathrm{~m}$ in the investigated area of the lake. In our case the dimensionless ratios for time, volumetric discharge, velocity and rotation can be computed as

$$
t_{R}=358 ; Q_{R}=89442719 ; v_{R}=22.36 \omega_{R}=0.0039
$$

In order to simulate the Earth's rotation, the model was hosted on a purposely built revolving table (Fig. 2a), with a diameter of $1.2 \mathrm{~m}$, controlled by a variable speed motor that can attain rotation rates between 0 and $20 \mathrm{rpm}$ with negligible vibrations. The platform accommodated the model and the instrumentation. According to the Rossby similarity, the revolving table was rotated with an angular speed of $0.177 \mathrm{rpm}$ about the center of gravity of the model so that a prototype day lasts $241 \mathrm{~s}$.

The model (Fig. 2a) was carved out of rigid polyurethane foam, by superimposing $2 \mathrm{~cm}$ thick sheets that were individually cut and smoothed on the basis of digital bathymetric curves derived from a high resolution elevation model of the lake bathymetry, in order to reproduce all essential topographic features of the lake. The sheets were attached one over the other using silicon glue, placed together within a protective rigid box, then suitably sanded and covered at the interior with a flexible liquid membrane for waterproofing. The discharge is injected at entrances $\mathrm{T} 1$ and $\mathrm{T} 2$, corresponding to the tributaries, by pipes controlled by 2 cylindrical Mariotte's bottles with a diameter of $22 \mathrm{~cm}$ and an height of $70 \mathrm{~cm}$. This simple system provides constant discharge during the experiment, simply by regulating the height of the bottle air inlet. Although the liquid could not be replenished in the Mariotte's bottle during operation, in our case this is not a constraint because of the very small volumes released during each test (less than $1200 \mathrm{~cm}^{3}$ ), when compared with the volume of the bottle, of about $28 \mathrm{~L}$. The tributary velocities at the inlet were controlled independently from the discharge by changing the diameter of the final part of each pipe. The level of the lake, measured through a gauge with a precision of $1 \mathrm{~mm}$, is kept constant during each test by operating a calibrated siphon at the outlet at the southern end of the lake. A wireless camera was positioned on the rotating table so that movies could be taken in the rotating reference frame during each experiment.

The model was operated in the following way. After filling the model with fresh water, we waited sufficiently long so that all transient motions disappeared. For thermally stratified experiments, an upper layer of warmer water was created by smoothly injecting warm water at the southern tip of the model in an area where a thin sheet of metal was laid slightly under the water surface, in order 
to prevent mixing during warm water injection. Then the valves of the pipes that convey water to the tributary mouths were opened and the rotating table set in motion, so that all the flow field can reach a steady state starting from rest before that the dye is injected. After a rotation spin up time (approximately $10 \mathrm{~min}$ ) during which the lake and the discharge from the tributaries and from the outflow were taken to a steady state, the temperature profile of the lake was measured in the first $15 \mathrm{~cm}$ at point M (Fig. 2b). The path of the tributary waters was then traced by injection of a colored dye made neutrally buoyant by water dilution and supplied from two injecting needles connected to the pipes carrying the inflows.

Over the last 3 years we have continuously monitored
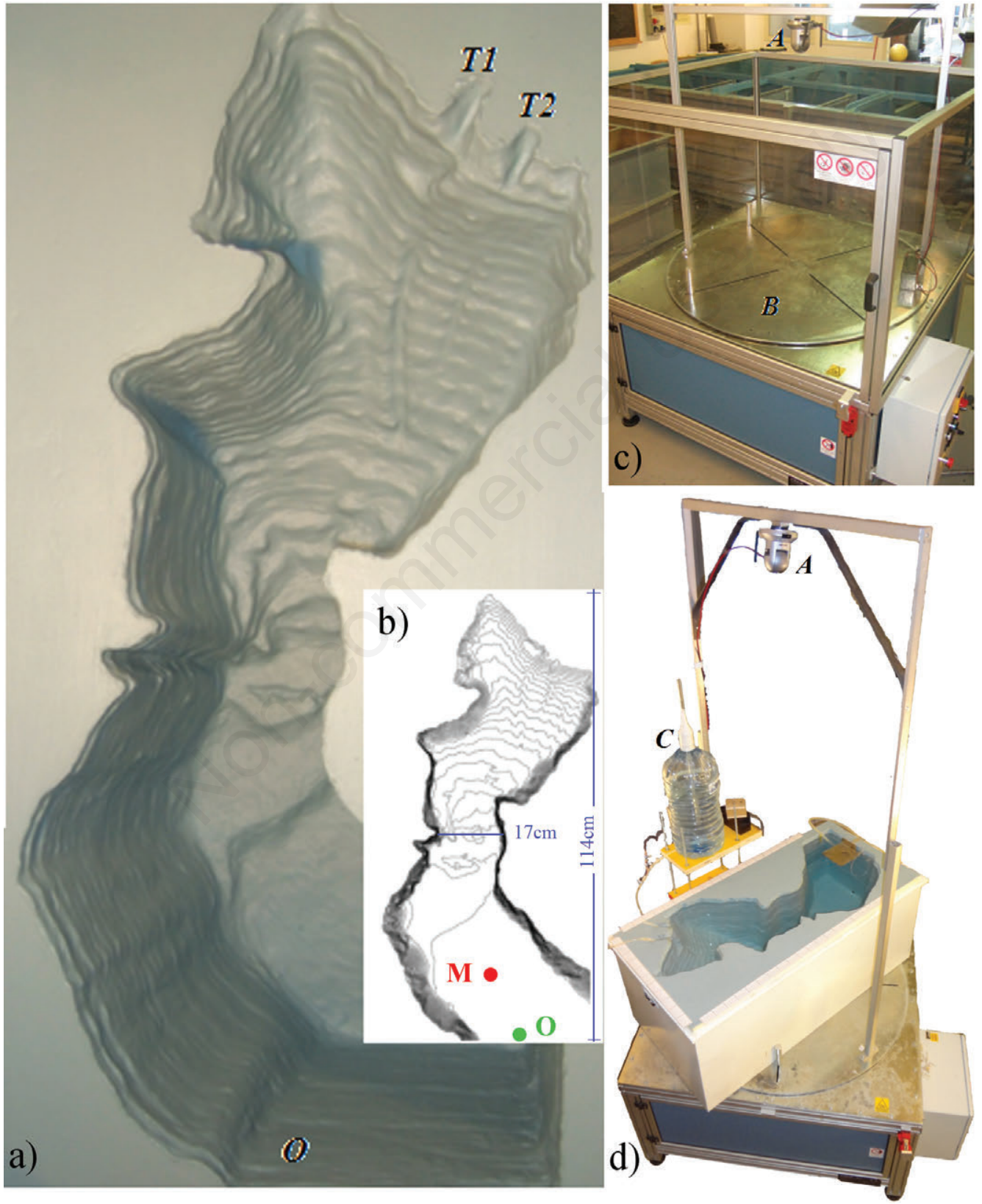

Fig. 2. Physical model of Lake Iseo (a) as derived from the isobaths shown in the inset (b); the $\mathrm{O}$ and $\mathrm{M}$ letter marks the position of the outlet and of the location of the temperature measurement. On the right, view of the revolving table B used in the experiments (c) and of the experimental setup (d). The C letter shows one of the Mariotte's bottle, while the A letter shows the position of the video camera, mounted on a frame rotating with the table. 
the temperature in the 2 main tributaries. The acquired data showed that between January and the end of March, when the lake has uniform temperature, the Oglio River is slightly warmer than the lake. Accordingly, during this period the Oglio River tends to overflow the lake waters. From the end of spring a sharp thermocline forms at a depth ranging from 6 to about $20 \mathrm{~m}$ below the surface and the temperature of the inflow is lower than that of the lake surface. Accordingly there is a tendency for the water of T1 and T2 to plunge to the neutral buoyancy depth, which ranges between 5 and $20 \mathrm{~m}$ in the period between May and November. In order to reproduce these effects, a thermally stratified system was used. The T2 inflow is always colder than the lake surface and it is structurally limited to no more than $50 \mathrm{~m}^{3} / \mathrm{s}$ so that its contribution is limited to ordinary discharges.

During the first set of experiments the temperature of the Oglio was kept $2^{\circ} \mathrm{C}$ higher than that of the lake surface. During the second set of experiments, an interflow situation was simulated. A typical stratified condition in the prototype is characterized by average temperatures of the epilimnion and hypolimnion of $20^{\circ} \mathrm{C}$ and $6.5^{\circ} \mathrm{C}$, respectively and of $14^{\circ} \mathrm{C}$ and $12^{\circ} \mathrm{C}$ for the tributary rivers; accordingly, the ratio of the density difference to the mean density, described in (2), is 0.00172 for the hypolimnetic and epilimnetic waters and 0.00117 for the average tributary water $\left(\mathrm{T}=13^{\circ} \mathrm{C}\right)$ and epilimnetic waters. During the experimental periods the water of the laboratory used to fill the model hypolimnion was at a temperature of about $13.5^{\circ} \mathrm{C}$. Accordingly, in order to match the prototype density ratio, an epilimnetic layer was created by operating with warm water at about $24^{\circ} \mathrm{C}$, obtaining an epilimnetic layer with a temperature between 22 and $23.5^{\circ} \mathrm{C}$. During these experiments the temperature of the tributaries, determined by the water within the Mariotte's bottles, was kept at an intermediate value of $18^{\circ} \mathrm{C}$. Accordingly the density ratio between hypolimnetic and epilimnetic $\left(\mathrm{T}=22.75^{\circ} \mathrm{C}\right)$ waters and between tributary and epilimnetic waters (eq. 2) were respectively 0.00171 and 0.001 , with a deviation of less than $15 \%$ with respect to the prototypal ratios.

Due to the relative shallowness of the epilimnetic layer and to the model spin-up period, it was impossible to recreate the exact prototype density distribution in the model. However, as already observed by Stewart (1988), this is not a severe problem provided that the investigated processes are not aimed to study the occurrence of internal waves and are limited to explore only the interflow process of the entering discharge immediately below the epilimnetic waters of the lake. Typical temperature profiles measured at $\mathrm{M}$ location (Fig. 2b) during the experiments are shown in Fig. 3.

In order to explore different operative and hydrologic conditions, the model inflows were scaled with respect to prototype discharges with different return periods (shown with bracketed letter T), as shown in Tab. 1. It is important to observe that in the watershed of Lake Iseo winter time is a drought period, so that floods typically occur when the lake is in stratified conditions. The average entrance velocity of the prototype tributaries were computed on the basis of the steady-state water surface profile obtained using the software HEC-RAS, based on the elevation of the lake surface, that can vary in the range of 184.85$186.25 \mathrm{~m}$ asl. As inevitable in physical models of large lakes, the Reynolds number is much smaller than the prototypal one, so that frictional effects at the entrance are probably overrated. Our effort to keep $Y_{R}$ as small as possible was motivated also by this need. Atkinson et al. (1994) operated with $Y_{R}=800$ and $\mathrm{Re}=200$ and similar or lower values may be expected in the other models presented in the literature. According to McClimans and Saegrov (1982), in order to improve the reproduction of mixing and entrainment, when possible $\mathrm{Re}>500$ should be attained and several of our simulation comply with this

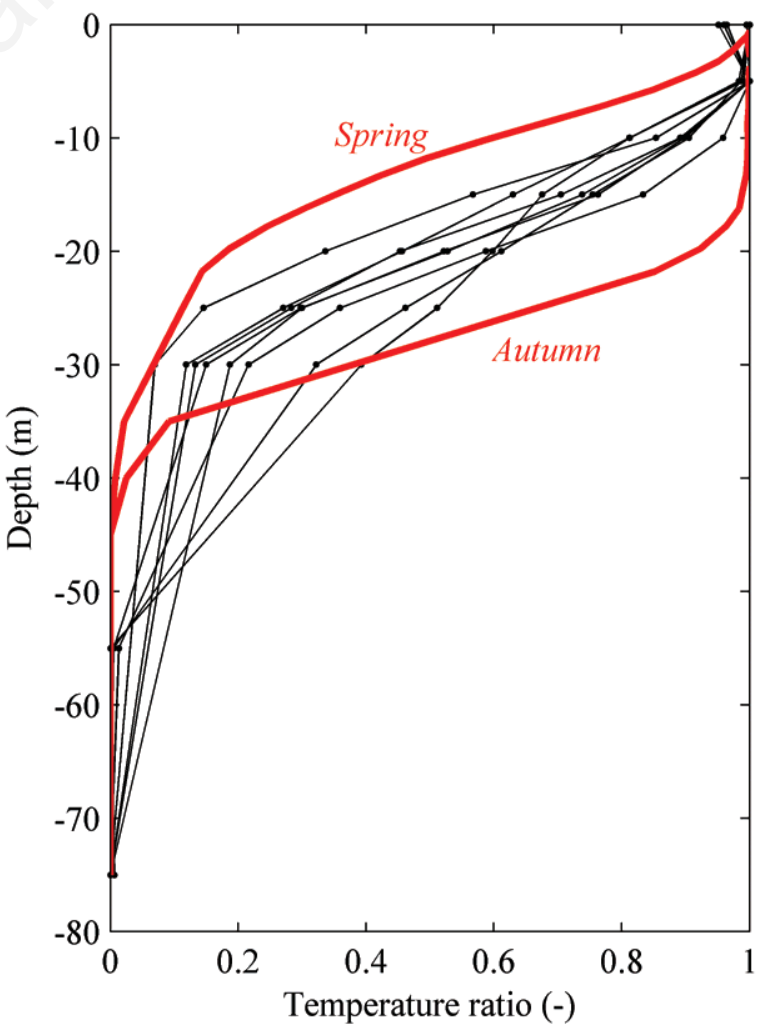

Fig. 3. Normalized temperature profiles measured at M location (see Fig. 2b) during the experiments accomplished in stratified conditions, rescaled to prototype depths (line with dots) and typical temperature profile measured in Lake Iseo during the spring and autumn season (thick lines). The temperature ratio was calculated as $\left(T-T_{\text {bottom }}\right) /\left(T_{\max }-T_{\text {bottom }}\right)$. 
condition. In order to evaluate the relevance of the different cases one should consider that, on the basis of the time series of discharge $\mathrm{Q}$ entering Lake Iseo in the period $1984-2011,36 \%$ of the volume was associated with $\mathrm{Q}<50$ $\mathrm{m}^{3} / \mathrm{s}, 78 \%$ with $\mathrm{Q}<100 \mathrm{~m}^{3} / \mathrm{s}$ and $98 \%$ with $\mathrm{Q}<300 \mathrm{~m}^{3} / \mathrm{s}$. Accordingly, one can expect that the experiments associated with $\mathrm{Q}<300 \mathrm{~m}^{3} / \mathrm{s}$ are the most significant for pollutant accumulation effects.

The results provided by the physical model were compared with different field data. On 21/07/2010 a drogue was released in front of $\mathrm{T} 2$ and retrieved 2 days later. The daily average discharges were $\mathrm{Q}_{\mathrm{T} 1}=14 \mathrm{~m}^{3} / \mathrm{s}$ and $\mathrm{Q}_{\mathrm{T} 2}=42$ $\mathrm{m}^{3} / \mathrm{s}$ and the corresponding average temperature $\mathrm{T}_{\mathrm{T} 1}=$ $16.5^{\circ} \mathrm{C}$ and $\mathrm{T}_{\mathrm{T} 2}=13.8^{\circ} \mathrm{C}$; wind (represented in Fig. $4 \mathrm{a}, \mathrm{b}$ ) was measured at a floating station located at point marked as LDS in Fig. 1. In the same position also the water temperature down to a depth of $50 \mathrm{~m}$ was measured by a thermistor chain. The same data were measured at point TC in Fig. 1. The water column was thermally stratified, with temperature ranging between $24^{\circ} \mathrm{C}$ and $6.4^{\circ} \mathrm{C}$, and a thermocline located around $11 \mathrm{~m}$. The drogue (shown schematically in Fig. $5 \mathrm{~b}, \mathrm{c})$ has a ratio $\mathrm{A}_{1} \mathrm{C}_{\mathrm{d} 1} / \mathrm{A}_{2} \mathrm{C}_{\mathrm{d} 2}$ of about 396 (where $A_{1}=8 \mathrm{~m}^{2}$ and $A_{2}=0.07 \mathrm{~m}^{2}$ are respectively the frontal area of the net and of the buoy and
$\mathrm{C}_{\mathrm{d} 1}=1.4$ and $\mathrm{C}_{\mathrm{d} 2}=0.4$ the corresponding drag coefficients), assuring that the drogue movements are governed by the force on the drogue and not by the force exerted by the wind on the buoy (Monahan and Monahan, 1973). The buoy contained a waterproof cavity in which a Geographical Positioning System GPS was located, transmitting its position with a planimetric precision of less than $10 \mathrm{~m}$ every $300 \mathrm{~s}$. During the experiment the depth of the drogue was $9 \mathrm{~m}$, corresponding to the intruding depth of $\mathrm{T} 2$ in front of which the drogue was set to drift. Additionally, on 05/07/2012 we used a multiparameter probe to acquire 44 vertical profiles of temperature, oxygen and turbidity in the northern part of the lake, with a vertical resolution of $0.5 \mathrm{~m}$. During the 3 days before the experimental campaign, ordinary wind conditions were present and the daily average discharges were $\mathrm{Q}_{\mathrm{T} 1}=16 \mathrm{~m}^{3} / \mathrm{s}$ and $\mathrm{Q}_{\mathrm{T} 2}=35 \mathrm{~m}^{3} / \mathrm{s}$ with average temperature $\mathrm{T}_{\mathrm{T} 1}=14.9^{\circ} \mathrm{C}$ and $\mathrm{T}_{\mathrm{T} 2}=13.9^{\circ} \mathrm{C}$. The water column was thermally stratified, with temperature ranging from 22 to $6.4^{\circ} \mathrm{C}$, and a thermocline located around $11 \mathrm{~m}$.

The tributary inflows entering Lake Iseo were also investigated with three-dimensional numerical model simulations. We adopted the hydrostatic version of the ELCOM model developed by the Centre for Water Re-
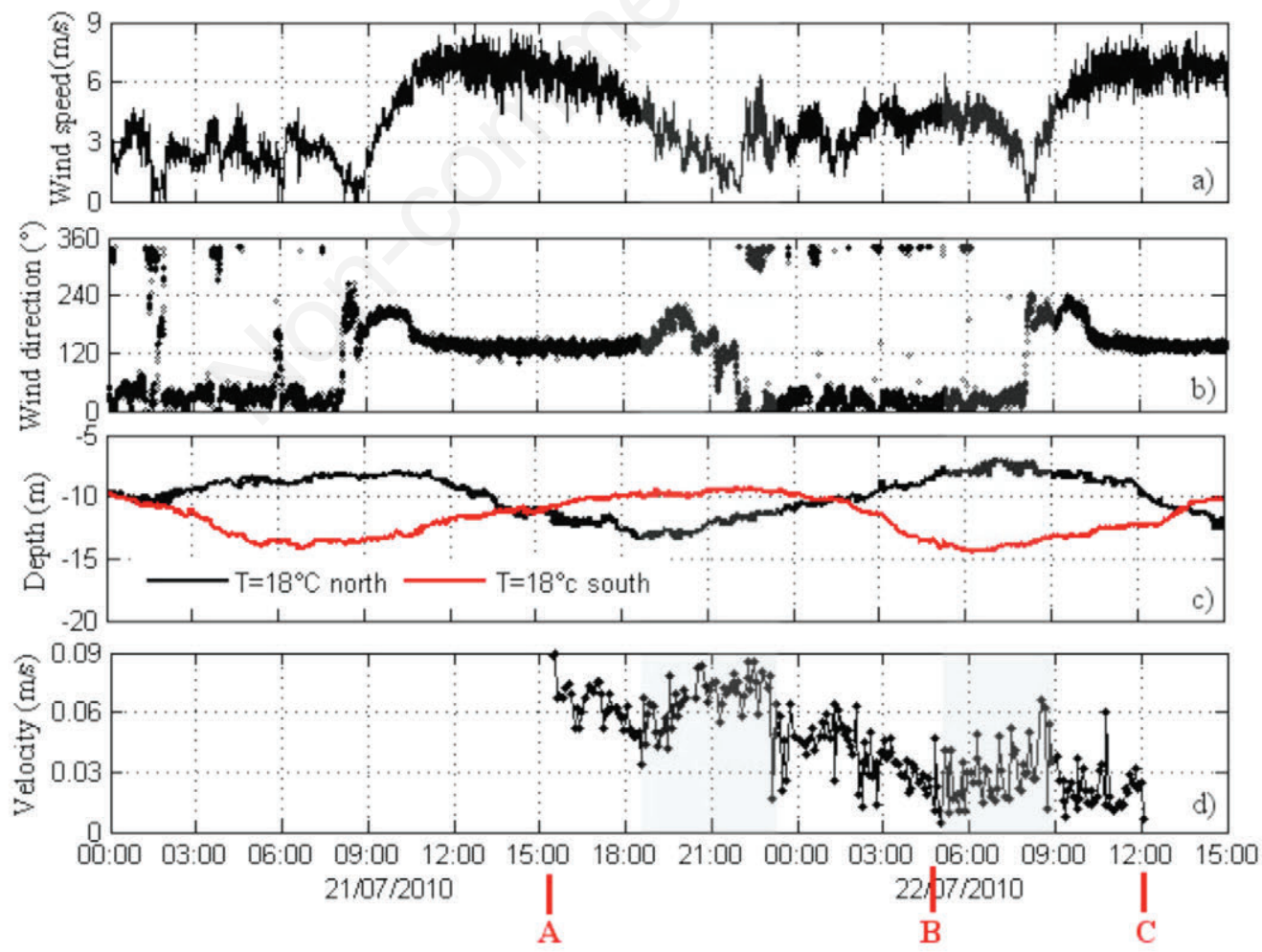

Fig. 4. Time series of the drogue velocity (d), wind speed and direction at the LDS station (a,b) and of the thermocline depths at LDS and TC stations (c) during the field experiment on 21-22/07/2010. In panel d), A,B and C refer to the instants marked with the same letters in Fig. 5a. 
search (CWR) of the University of Western Australia, which was extensively used in the literature to investigate the hydrodynamics of lakes and reservoirs, including lakes that are subject to inflow forcing (Morillo et al., 2008; Marti et al., 2011). ELCOM solves the Reynolds averaged Navier Stokes equations with the Boussinesq approximation for density differences using a semi-implicit formulation on a finite-volume framework (Hodges et al., 2000). Baroclinic and barotropic responses, rotational effects, wind stresses, surface thermal forcing, inflows, outflows, and transport of heat and passive scalars are included in the code.

In this work, ELCOM was configured to simulate the 3D flow fields in Lake Iseo under the inflows and outflow forcing only, providing a comparison to the results of the physical model during the stratified period. We used a 60$\mathrm{m}$ grid size in the northern part of the lake, maintaining a $300 \mathrm{~m}$ resolution in the other parts of the domain. The horizontal grid was combined with a vertical resolution of $1 \mathrm{~m}$ in the first $20 \mathrm{~m}$ depth, where the inflows typically intrude, followed by layers with gradually increased thickness up to $10 \mathrm{~m}$ for the deepest layer. To guarantee stability in the computations, simulations were run using a $60 \mathrm{~s}$ time step. Each cell of the domain was initialized with zero velocity, and with a vertical temperature profile that characterizes the typical summer stratification. The model was then forced by the discharges and velocity of cases (1B-7B, 1C) in Tab. 1, with no wind or radiative forcings. According to the averaged temperature measurements accomplished in the last 3 years, the temperature of Oglio and Canal were set to $15^{\circ} \mathrm{C}$ and $13^{\circ} \mathrm{C}$, respectively. After a spin-up time sufficient to establish a quasi-steady state flow (10 days), two conservative tracers were continuously released from the inflows at a constant concentration to track the two inflow paths under a reasonably steady-state condition. Each simulation took approximately $18,000 \mathrm{~s}$ with a I7 processor and 4GB RAM.

\section{RESULTS}

Snapshots taken at variable prototype time between $\mathrm{t}=3$ hours and 23 hours are shown in Fig. 6, where symbols are taken from the rightmost column of Tab. 1. The experiments reproducing plume intrusions do not show a marked difference with respect to those where an overflow occurs, although in the intrusion case the tracer is more confined whilst in the overflow case there is a stronger lateral dispersion. In general, a good reproducibility was observed from test to test, although in stratified conditions it is almost impossible to recreate the exact density gradients, so that slight variations can be present.

As a starting point, if the model is not rotated the plume follows a straight line moving offshore in front of the tributary mouths, as shown in case $1 \mathrm{C}$ and confirmed

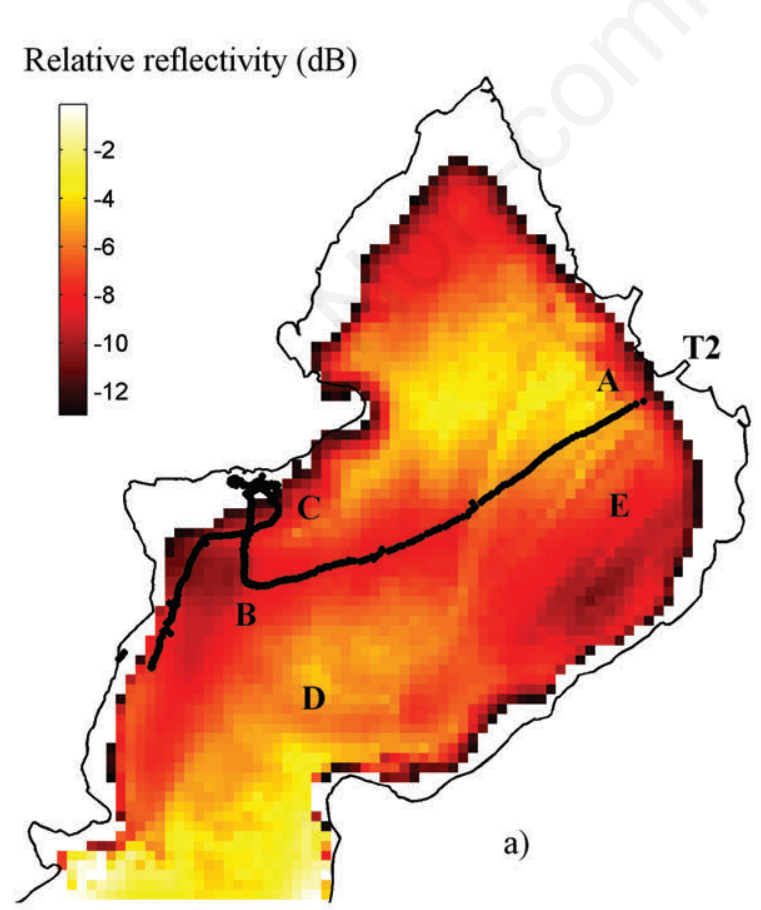

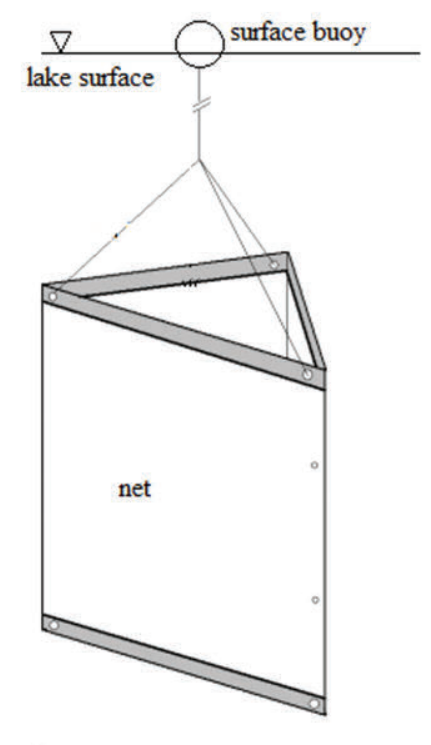

b)

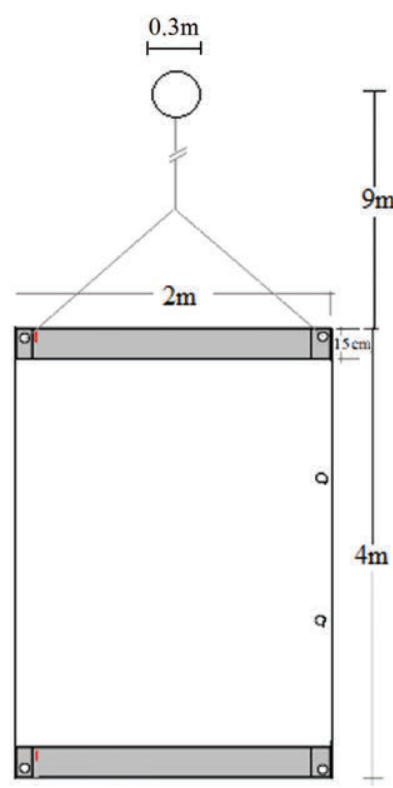

c)

Fig. 5. a) Map showing the relative basal reflectivity map $(\mathrm{dB})$ of the lake bottom superimposed to the path of the drogue deployed on 21/7/2010 in front of the Industrial canal (point A in front of T2), at $9 \mathrm{~m}$ of depth. b,c) Scheme of the drogue used for the lagrangian measurement. 
also by numerical simulations accomplished by neglecting the Coriolis force. The plume shows an eastward deflection only when it gets close to the Trentapassi Peninsula, due to a purely bathymetric effect that is likely related to an imbalance of the lateral water entrainment, similar to the Coanda effect discussed by Hamblin and Carmack (1978). When Earth's rotation is accounted for, the effect of Coriolis force is clearly noticeable in all the experiments but for the highest discharge (see 6B and 7B), where the action of the Coriolis force can be observed only farther south. This is due to the high discharge momentum, that overwhelms the Coriolis effect, at least in the near-field, as confirmed by the Rossby number in these two cases $(R o=9.5$ in $6 \mathrm{~B}$ and $R o=12$ in $7 \mathrm{~B}$, computed with $\mathrm{L}=3000 \mathrm{~m}$ and the tributary velocity). These simulations were performed only in thermally stratified conditions because high discharges typically occur between spring and the end of fall. Apart from these cases, when $\mathrm{Q}<100 \mathrm{~m}^{3} / \mathrm{s}$ the typical velocities of the plume in the area in front of the tributary entrances, as shown by the drogue velocities in Fig. 4d, should be in the order of a few $\mathrm{cm} / \mathrm{s}$, so that the Rossby number, computed with $\mathrm{L}=1700 \mathrm{~m}$ (i.e., the distance between the inlets and the tip of the Castro Peninsula) is in the range 0.1-0.5. In these experiments both the $\mathrm{T} 1$ and $\mathrm{T} 2$ plumes show a clear tendency to curve westward toward the shoreline of Castro Peninsula, forcing a clockwise gyre within the Lovere bay. For the lowest values of the Rossby number (cases from $1 \mathrm{~A}-1 \mathrm{~B}$ to $3 \mathrm{~A}-3 \mathrm{~B}$ ), the tip of the Castro Peninsula splits the plume, so that the clockwise gyre within the Lovere bay is reinforced by the direct action of the plume itself. In these cases the prototypal inertial radius $v /\left(2 \omega_{P} \sin (\varphi)\right)$, where $v$ is the plume's velocity and $\varphi$ is the Lake Iseo's latitude, is comparable to the radius of the circle that could be inscribed within the gulf, so that the Earth's rotation and the shear force exerted by the plume reinforce each other in driving the gyre.

In thermally stratified conditions (1B, $2 \mathrm{~B}$ and $3 \mathrm{~B}$ ), the plume impinges on the Castro Peninsula a little farther south and moves eastward more strongly, so that the plume passes under the Corna Trentapassi Mountain. In this case, farther south the plume moves eastward again, although this part of the domain is outside of the area described here. In general the plume drives another slow anticlockwise gyre that moves backward towards the area of Pisogne (clearly noticeable in case 2A and 2B), along the east shore of the lake. In some experiments this large return gyre feeds secondary and smaller vortexes that move southward along the shore.

ELCOM was used to simulate the inflow of the Oglio River and of the Industrial canal entering Lake Iseo in absence of wind. A temperature regime representative of the summer season and several hydrological scenarios were considered. Under these conditions, according to the model both the inflows intrude under the water surface in the upper metalimnion (between $7 \mathrm{~m}$ and $10 \mathrm{~m}$ ) and then propagate horizontally into the lake, in agreement with the data provided by cross transects of vertical turbidity profiles accomplished in July 2012 (unpublished data, see Fig. $7 \mathrm{~b}$ for an example) in the same area.

In Fig. 8 the velocity field and the tracer distribution provided by the numerical model in time and space at the intrusion depth were compared with the experimental results. Under ordinary flow conditions (1B-2B), the intrud-

Tab. 1. Prototype conditions simulated with the model. Q is the volumetric discharge and $U$ the average velocity of the tributaries. The densimetric Froude number for the stratified conditions is based on the density difference between tributary and epilimnetic waters; the Reynolds number is referred to the model and was computed as $4 \mathrm{UR} / \mathrm{v}$, where here $\mathrm{v}$ is the kinematic viscosity of the water, while $\mathrm{U}$ and $\mathrm{R}$ are the average velocity and the hydraulic radius of the incoming jet. The T letter within round brackets shows the return period, in years, and the identifier ID makes reference to snapshots in Fig. 6.

\begin{tabular}{|c|c|c|c|c|c|c|c|}
\hline Thermal condition & $\begin{array}{c}\mathrm{Q}_{\mathrm{T1}} \\
\left(\mathrm{m}^{3} / \mathrm{s}\right)\end{array}$ & $\begin{array}{c}\mathrm{Q}_{\mathrm{T} 2} \\
\left(\mathrm{~m}^{3} / \mathrm{s}\right)\end{array}$ & $\begin{array}{c}\mathrm{U}_{\mathrm{T1}} \\
(\mathrm{m} / \mathrm{s})\end{array}$ & $\begin{array}{c}\mathrm{U}_{\mathrm{T} 2} \\
(\mathrm{~m} / \mathrm{s})\end{array}$ & $\begin{array}{l}\mathrm{Fr} \\
(-)\end{array}$ & $\begin{array}{l}\operatorname{Re} \\
(-)\end{array}$ & ID \\
\hline Homogeneous; overflow & $\begin{array}{c}50 \\
- \\
25 \\
100(\mathrm{~T}=1 \mathrm{y}) \\
300(\mathrm{~T}=2 \mathrm{y})\end{array}$ & $\begin{array}{l}- \\
50 \\
25 \\
- \\
-\end{array}$ & $\begin{array}{c}0.5 \\
- \\
0.3 \\
0.5 \\
1.5\end{array}$ & $\begin{array}{c}- \\
0.5 \\
0.3 \\
-\end{array}$ & & $\begin{array}{c}142 \\
142 \\
71 \\
178 \\
534\end{array}$ & $\begin{array}{l}1 \mathrm{~A} \\
2 \mathrm{~A} \\
3 \mathrm{~A} \\
4 \mathrm{~A} \\
5 \mathrm{~A}\end{array}$ \\
\hline Stratified; interflow & $\begin{array}{c}50 \\
- \\
25 \\
100(\mathrm{~T}=1 \mathrm{y}) \\
300(\mathrm{~T}=2 \mathrm{y}) \\
500(\mathrm{~T}=10 \mathrm{y}) \\
770(\mathrm{~T}=100 \mathrm{y})\end{array}$ & $\begin{array}{l}- \\
50 \\
25 \\
- \\
- \\
- \\
-\end{array}$ & $\begin{array}{c}0.5 \\
- \\
0.3 \\
0.5 \\
1.5 \\
3 \\
4\end{array}$ & $\begin{array}{l}- \\
0.5 \\
0.3 \\
- \\
- \\
- \\
-\end{array}$ & $\begin{array}{c}4.1 \\
4.1 \\
2.0 \\
2.5 \\
7.5 \\
17.5 \\
19.3\end{array}$ & $\begin{array}{c}142 \\
142 \\
71 \\
178 \\
534 \\
1017 \\
1370\end{array}$ & $\begin{array}{l}1 \mathrm{~B} \\
2 \mathrm{~B} \\
3 \mathrm{~B} \\
4 \mathrm{~B} \\
5 \mathrm{~B} \\
6 \mathrm{~B} \\
7 \mathrm{~B}\end{array}$ \\
\hline Stratified; interflow; no Earth rotation & 50 & - & 0.5 & - & 4.1 & 142 & $1 \mathrm{C}$ \\
\hline
\end{tabular}



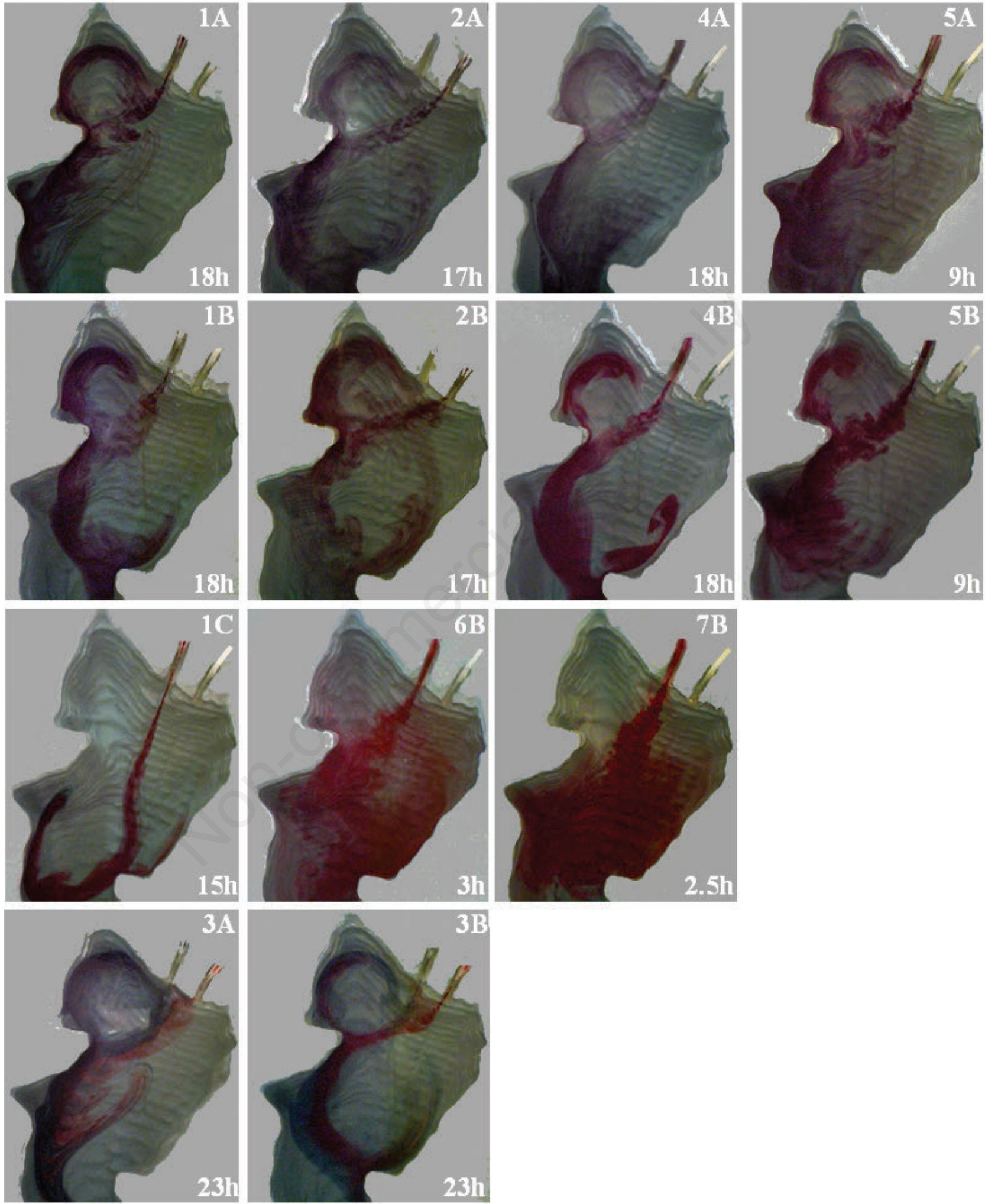

Fig. 6. Comparison between flow fields in thermally homogeneous (A), stratified (B) and no rotation (C) conditions. The prototypal time of each snapshot is shown. See Tab. 1 for symbols. 
ing plume is characterized by a westward deflection. The numerical inflow path reproduces very well the experimental one in the first stages of the intrusion, reaching the Castro promontory approximately $7 \mathrm{~h}$ after the release (1B and 2B). In the next few hours, a clockwise vortex forms in the Lovere bay with temporal and spatial pattern very close to the ones observed in the physical model. The numerical simulation, instead, does not evidence the counter-clockwise vortex on the eastern shore, since most of the inflow-driven current tends to flow south. However, the plume exerts a water entrainment from the surrounding waters so that this counterclockwise vortex must be present in the prototype and the numerical simulations suggest that it is possibly weaker than would appear from the experiments. An analogous flow structure can be observed when both the two inflows are present but with lower discharges (3B). In such a case, the numerical results show that more of the Oglio River moves into the Lovere bay. It is also interesting to notice that in the experiment, the Oglio tracer mainly contributes to the vortex in the Lovere bay. In agreement with the experimental results, under a flood condition (6B, T $=10$ years) ELCOM shows a relevant reduction of the plume deflection; accordingly, the Oglio tracer does not enter the Lovere bay, both for the physical and the numerical model. In this case, the counter-clockwise vortex is evident also in the numerical results, although with a slower velocity.

\section{DISCUSSIONS}

The obtained results shed light on some intriguing behaviour of the flow field in the northern part of Lake Iseo. The Coriolis force proves to be a relevant driver in the entrance area of the tributaries also for medium-size lakes. This confirms the results by Nydegger (1979), who pro- vided some clues on the role of inflowing rivers as major driving forces for water circulation in Lakes Brienz and Biel, two medium size lakes in north-western Switzerland. Although the overall flow field in the prototype can be often influenced or even dominated by the direct and indirect action exerted by wind, the interest in studying the Coriolis effect in itself, independently from the wind, arises from the consideration that the influence of the Earth's rotation is steady in time, unlike the wind induced flows. Accordingly one may expect that Coriolis force has a role in determining properties related to the time integrated flow field over long periods. Moreover, as observed by other authors (Kang-Ren et al., 2002) the Coriolis force may become an important factor under calm wind situations, when internal waves are unimportant. Considering the level of uncertainty that is present in a distorted model, where the complexity of the prototype is partly lost, the results must be considered to be suggestive only, providing further evidence of the validity of our modelling conclusions.

A first comparison can be done on the basis of a lagrangian measurement using the drogue shown in Fig. 5a, that was accomplished on the $21^{\text {th }}$ of July 2010 . According to the rivers discharges and temperature, the inflowing conditions are intermediate between those of experiments 2B and 3B of Fig. 6. Fig. 5a shows the recorded trajectory of the drogue. As one can see its trajectory shows the same westward curved pattern of the experiment between points A and B, although not as strongly as in Fig. 6. A subsequent sudden change in velocity is evident, which takes the buoy to point $\mathrm{C}$. Both these effects are connected to the presence of a significant field of internal waves during the stratified period (Valerio et al., 2012). In order to better appreciate this point, it is useful to observe Fig. 4, where wind and the thermocline depth measured at LDS
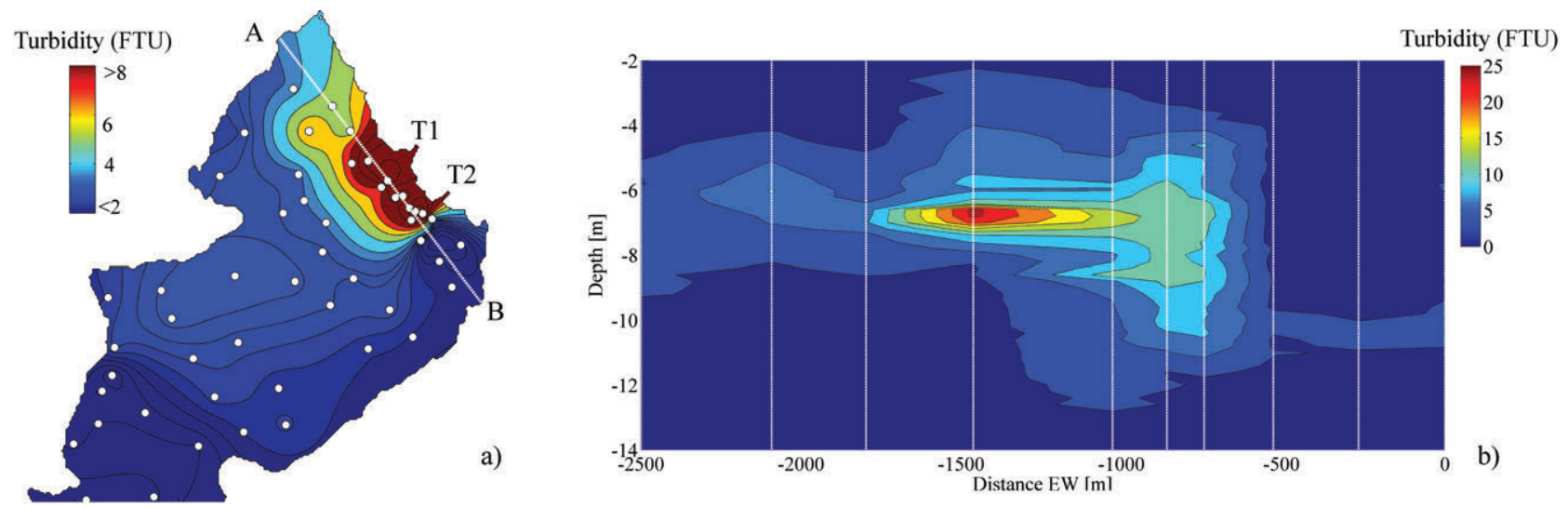

Fig. 7. Spatial distribution of turbidity (FTU units) measured on the 05/07/2012 between 6-8 m of depth (a) and along a cross-section $\mathrm{AB}$ (b). The white broken line in the a) panel shows the position of the cross-section AB. The sampling locations are marked with dots (a) and with white broken lines (b). 
and TC stations are shown along with the computed speed of the drogue. The time series of the computed velocity (Fig. 4d) shows two ascending periods (between 18:00 and 23:00 of 21/07 and between 5:00 and 9:00 of 22/07, shaded in Fig. 4) which start simultaneously with the maximum vertical deflection of the thermocline (Fig. 4c), when the wind starts decreasing (Fig. 4b). Due to the thermocline gradient, a mass movement from north to south is associated with the first period, whilst a movement from south to north is associated with the second one. Whilst the second northward movement clearly explains the BC stretch of the drogue (Fig. 5), the increase of the southward velocity during the first period locally increases the Rossby number, counteracting the action of Coriolis force in the AB stretch. This example clearly shows that the superimposition of several dynamic effects in the prototype does not necessarily cancel the overall effect of the Coriolis force.

In Fig. 5a the trajectory is superimposed on the reflectivity map measured during the bathymetric survey of the lake bottom by Regione Lombardia in 2002 (Bini et al., 2007). The signal received by the multibeam system used during the survey was composed of information about the travel time, used to measure the local depth of the bottom, and information about the ratio between the energy of the sent and received pulse; this ratio, suitably corrected and averaged, provides the reflectivity (in $\mathrm{dB}$ ) of the bottom. The values of reflectivity shown in a chromatic scale in the map can be associated both to changes in the type of sediment on the bottom and to their roughness. From the map the presence of more reflective sediments is evident in correspondence with the drogue trajectory and, in general, of the plume. Provided that the entering plumes have fine-grained sediment initially kept in suspension by turbulence, it is reasonable to expect a correlation between the prevailing direction of the current and the pattern of sediment composition at the bottom. These sediments also characterize the area close to the lower left corner, where the experiments show that the plume tends to accumulate. The map seems to suggest the presence of a curved pattern that follows the backward gyre evidenced during most of the experiments (see point D) as well as of local maxima (point E) corresponding to the entrance of an active creek (Trobiolo) or of an ancient bed position of the T1 tributary. Accordingly, the correspondence between sedimentological units and Coriolis related currents, that has been observed by several authors (Nydegger, 1979; Wright and Nydegger, 1980; Hamblin and Carmack, 1978; Hakanson
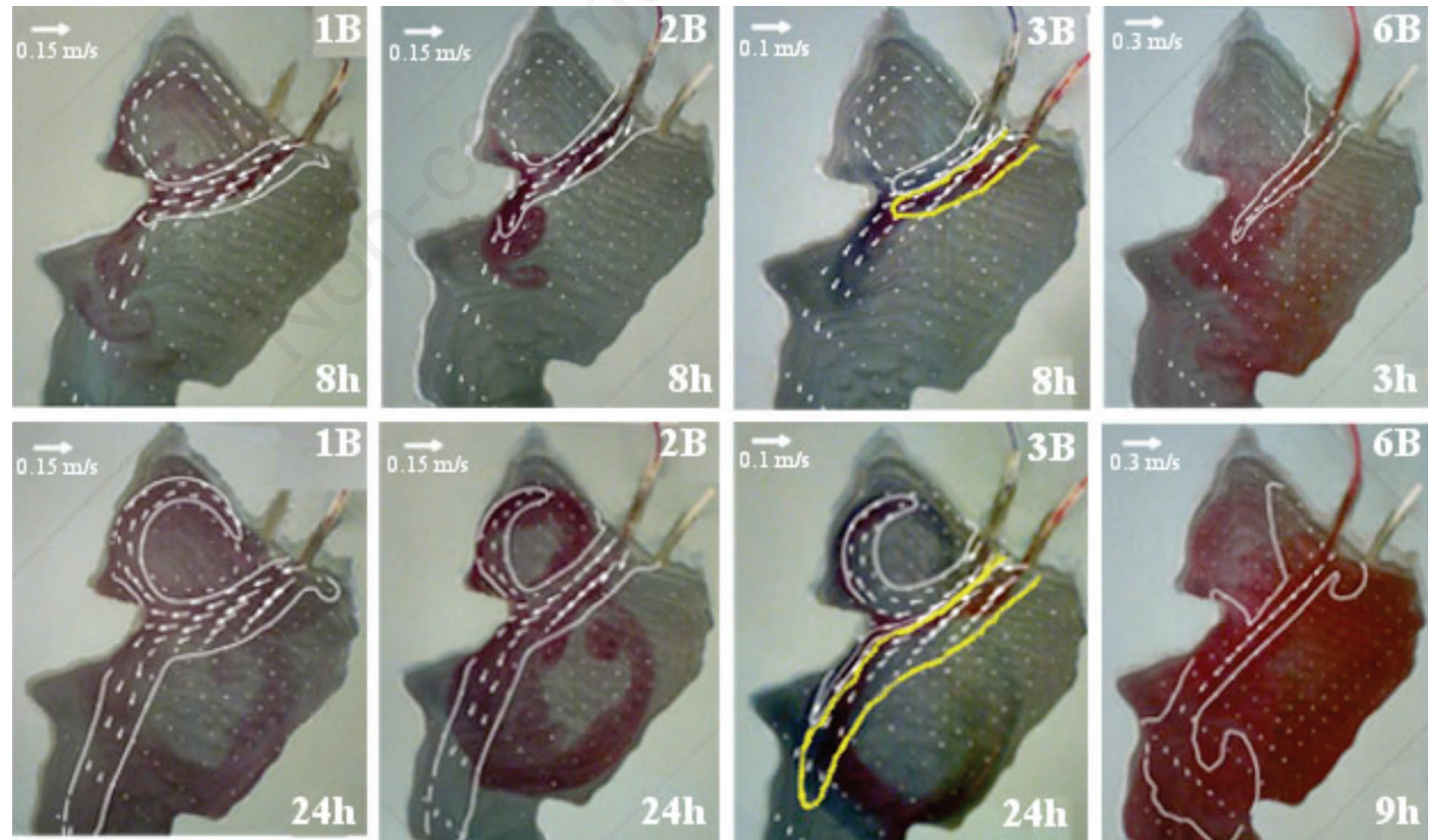
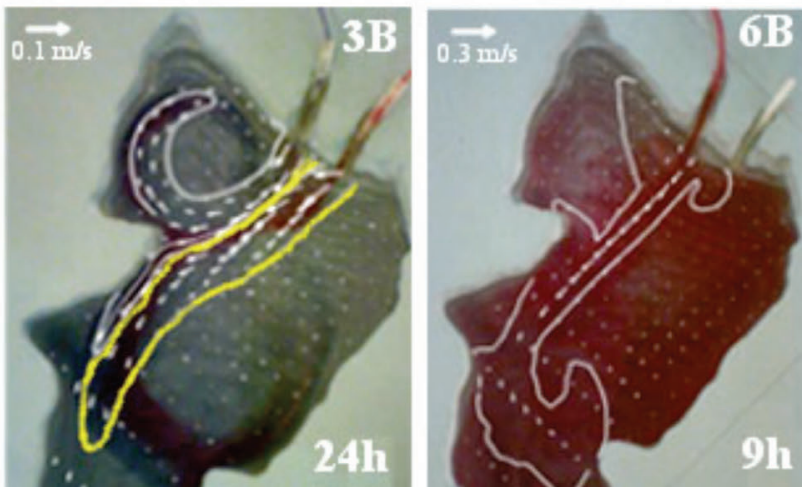

Fig. 8. Comparison between the inflow path obtained from the experiments and from the numerical simulations. The snapshots taken in the laboratory are superimposed to the numerical flow field (scaled arrows) and tracer field (contour line corresponding to $10 \%$ of the initial concentration of the tracer) computed at the same instant. 
and Janson, 1983) seems supported also by this research. Altogether, we think that these circulation patterns could help to understand the bottom dynamic processes that are of vital importance for a proper interpretation of sediment data and those related to the deposition within the lake of river-borne pollutants, such as mercury pollution, as observed by Hakanson (1974).

Finally, in the light of the results provided by the physical model, it is interesting to consider the measurements accomplished in Lake Iseo during the monitoring campaign of July 2012. In Fig. 7 a cross section of turbidity throughout the water column in front of the tributaries is shown, from which it can be seen that the interflow of entering discharge occurs at a depth of about $7 \mathrm{~m}$. In Fig. 7a the interpolated and averaged map of turbidity in the depth range 6-8 $\mathrm{m}$ is shown, along with the gauging locations. Although the distribution of water turbidity is affected by the overall flow field, which are strongly conditioned by the winds, this map shows that there is a clear match between the influence areas identified by the physical model and the distribution of water turbidity. There is a match both in terms of west-east gradient and of the local maximum along the shore of Castro. Accordingly, these experimental results also confirm that the effect of the Coriolis force is present and is not masked by the other dynamic effects which affect the lake flow field.

\section{CONCLUSIONS}

This paper concerns a physical model study of Lake Iseo, aimed to provide a contribution to understanding the water circulation in the northern part of the lake, characterised by the entrance of the two main tributaries. Although Lake Iseo is the fifth Italian lake in terms of volume, very few studies have so far investigated its hydrodynamics.

The obtained experimental data show that the river plumes of the Oglio River and of the Industrial canal entering Lake Iseo are strongly influenced by the Earth's rotation which deflects the plume toward the right (west) of the lake, forcing a dominant vortex in the Lovere bay and a secondary one along the north-eastern part of the lake. Although the actual pattern of flow field is exceedingly complex and determined by the interaction of multiple forcings acting on the lake, such as the wind field and the associated internal wave activity (Valerio et al., 2012), the Coriolis force can influence the average flow. Understanding the influence of the Coriolis force could help to indentify the areas that are more prone to river-borne bacterial pollution or other contamination, providing some guidance to the overall water quality management of this lake. This is confirmed by other data that have been measured during different experimental campaigns: drogue trajectory, reflectivity data, turbidity concentration. A 3D numerical model of this part of the lake confirms the general findings of this research.

\section{ACKNOWLEDGMENTS}

The physical model was built by Luisa Paterlini and Nicola Tolentini who are gratefully acknowledged. Thanks are due to Regione Lombardia and to Dott. Andrea Piccin for making the reflectivity data available. Finally, the authors acknowledge the use of the models (ELCOM) developed by the Centre for Water Research, University of Western Australia, and the anonymous reviewers for their valuable contribution to the improvement of the paper.

\section{REFERENCES}

Ambrosetti W, Barbanti L, 2005. Evolution towards meromixis of Lake Iseo (Northern Italy) as revealed by its stability trend. J. Limnol. 64:1-11.

Atkinson JF, Lin G, Joshi M, 1994. Physical model of Niagara River discharge. J. Great Lakes Research 20:583-589.

Bini A, Corbari D, Falletti P, Fassina M, Perotti CR, Piccin A, 2007. Morphology and geological setting of Iseo Lake (Lombardy) through multibeam bathymetry and high-resolution seismic profiles. Swiss J. Geosci. 100:23-40.

Bonomi G, Gerletti M, 1967. [Il Lago d'Iseo: primo quadro limnologico generale (termica, chimica, plancton e benton profondo)].[Article in Italian]. Mem. Ist. Ital. Idrobiol. 22: 149-175.

Brizzio MC, Garibaldi L, Leoni B,Mosello R, 2001. [La stabilizzazione della stratificazione chimica del Lago di Iseo e le sue implicazioni sulle caratteristiche biologiche].[Article in Italian]. Atti Assoc. Ital. Oceanol. Limnol. 14: 125-136.

Dortch MS, Wilhelms SC, Holland JP, 1985. Physical modeling of reservoir hydrodynamics. Technical report, U.S. Army Engineer Waterways Experiment Station.

Fischer HB, Smith RD, 1983. Observation of Transport to surface waters from a plunging inflow to Lake Mead. Limnol Oceanogr. 28:258-272.

Garibaldi L, Mezzanotte V, Brizzio MC, Rogora M, Mosello R, 1999. The trophic evolution of Lake Iseo as related to its holomixis. J. Limnol. 62:10-19.

Hakanson L, 1974. Mercury in some Swedish lake sediments. Ambio 3:37-43.

Hakanson L, Janson M, 1983. Principles of lake sedimentology. Springer, Berlin, Germany.

Hamblin RE, Carmack EC, 1978. River-induced currents in a Fjord Lake. J. Geophys. Res. 63:885-899.

Harleman DRF, Holley E, Hoopes J, Rumer RR, 1962. The feasibility of a dynamic model study of Lake Michigan, Mich. Univ. Great Lakes Res. Div. Publ. 9:51-67.

Hodges BR, Imberger J, Saggio A, Winter KB, 2000. Modeling basin-scale motions in a stratified lake. Limnol. Oceanogr. 45:1603-1620.

Hogg CAR, Marti CL, Huppert H, Imberger J, 2013. Mixing of an interflow into the ambient water of Lake Iseo. Limnol. Oceanogr. 58:579-592.

Laborde S, Antenucci JP, Copetti D, Imberger J, 2010. Inflow intrusions at multiple scales in a large temperate lake. Limnol. Oceanogr. 55:1301-1312.

Li C, Kisser KM, Rumer RR. 1975. Physical model study of cir- 
culation patterns in Lake Ontario, Limnol. Oceanogr. 203:323-337.

Kang-Ren J, Zhen-Gang J, Hamrick JH, 2002. Modeling winter circulation in Lake Okeechobee, Florida. J. Waterw. Port C. Div.-ASCE 128: 14-125.

Marti CL, Mills RB, Imberger J. 2011. Pathways of multiple inflows into a stratified reservoir: Thomson Reservoir, Australia. Adv. Water Res. 34:551-561.

McClimans TA, Saegrov S, 1982. River plume studies in distorted Froude Models. J. Hydraul. Res. 20:15-27.

Monahan EC, Monahan EA, 1973. Trends in drogue design. Limnol. Oceanogr. 18:981-985.

Morillo S, Imberger J, Antenucci JP, Woods PF, 2008. The influence of wind and Lake Morphometry on the interaction between two rivers entering a stratified lake. J. Hydraul. Eng. 134:1579-1589.

Nydegger P, 1979. Water circulation in lakes. Research in situ, using revolving lake-models (As Shown In The Film) and comparisons with the latest limnosedimentological results. Dev. Water Sci. 11:161-170.

Peronaci F, 1949a. [Le sesse del Lago di Iseo. Parte prima]. [Article in Italian]. Annali di Geofisica 2:267-280.
Peronaci F, 1949b. [Le sesse del Lago di Iseo. Parte seconda]. [Article in Italian]. Annali di Geofisica 2:406-416.

Pilotti M, Valerio G, Leoni B, 2013. Data set for hydrodynamic lake model calibration: a deep pre-alpine case. Water Resour. Res. 49:7159-7163.

Rumer RR, Robson L, 1968. Circulation studies in a rotating model of Lake Erie. State University of New York at Buffalo: 36 pp.

Salmoiraghi F, 1898. [Contributo alla limnologia del Sebino con un abbozzo di carta batometrica]. [Book in Italian]. Tip. Bernardoni ed., Milan: 61 pp.

Stewart KM, 1988. Tracing inflows in a physical model of Lake Constance. J. Great Lakes Res. 14:466 478.

Valerio G, Pilotti M, Marti CL, Imberger J, 2012. The structure of basin scale internal waves in a stratified lake in response to lake bathymetry and wind spatial and temporal distribution: Lake Iseo, Italy. Limnol. Oceanogr. 57:772-786.

Vilhena L.C., Marti C.L., Imberger J., 2013. The importance of nonlinear internal waves in a deep sub-alpine lake: Lake Iseo. Limnol. Oceanogr. 58:1871-1891.

Wright RF, Nydegger, 1980. Sedimentation of detrital particulate matter in lakes: Influence of currents produced by inflowing rivers. Water Resour. Res. 16:597-601. 